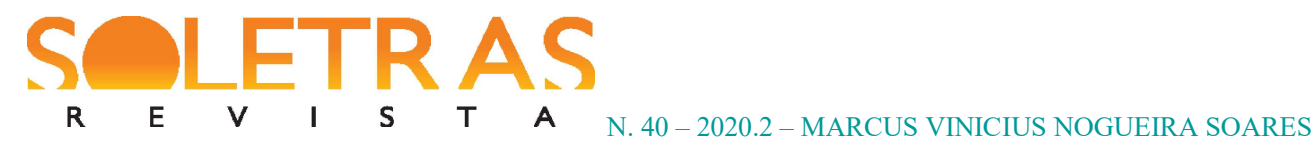

\title{
José de Alencar no Diário do Rio de Janeiro
}

\author{
Marcus Vinicius Nogueira Soares ${ }^{1}$
}

\begin{abstract}
Resumo: Entre outubro de 1855 e julho de 1858, José de Alencar ocupou o cargo de redator em chefe do jornal Diário do Rio de Janeiro. Durante esse período, foi responsável pela publicação de diversas obras, sobretudo de sua própria autoria, nas páginas do Diário, contemplando vários gêneros discursivos, de crítica literária a romance, passando por libreto de ópera, biografia, entre outros. Em apenas três anos de atuação à frente do jornal, Alencar tornou-se um nome reconhecido no círculo letrado da época. O momento foi tão fértil que algumas dessas obras permanecem até hoje em evidência na fortuna crítica do autor, como Cartas sobre a Confederação dos Tamoios e $O$ guarani. Considerando as condições materiais de produção e difusão características do jornalismo de meados do século XIX que tornaram possível a experiência pública dessas obras, o presente artigo analisa a importância desse momento inicial da carreira de José de Alencar para a compreensão de sua trajetória intelectual e literária.
\end{abstract}

Palavras-chave: José de Alencar. Romance brasileiro. Jornalismo oitocentista.

\section{Introdução}

Em outubro de 1855, logo após a sua saída do Correio Mercantil, José de Alencar assumiu a direção de outro grande jornal carioca da época, o Diário do Rio de Janeiro, permanecendo na nova função até julho de 1858. Durante quase três anos, além de exercer atividades tipicamente jornalísticas, como referendar matérias que seriam publicadas diariamente pelo jornal e escrever artigos de fundo, Alencar ainda encontrou tempo para ampliar o seu campo de atuação, produzindo e publicando, nas páginas do Diário, crítica literária, biografia, romance e teatro. Essa ampliação parecia fazer parte de um projeto que se desdobrava em outro empreendimento realizado por ele ao longo de sua gestão: valendo-se da tipografia do próprio jornal, o autor de Iracema editava em volume tanto as suas obras quanto as de outros autores que também vinham sendo divulgadas na folha. Embora tal prática fosse comum na imprensa da época, chama a atenção o expediente de autopublicação associado ao

\footnotetext{
${ }^{1}$ Doutor em Literatura Comparada pela Universidade do Estado do Rio de Janeiro (1999). Atualmente é professor associado da Universidade do Estado do Rio de Janeiro. Tem experiência na área de Letras, com ênfase em Literatura Brasileira, atuando principalmente com os seguintes temas: história literária, folhetim e crônica oitocentistas, romance brasileiro do século XIX e a obra de José de Alencar. Brasil. E-mail: soaresmarcus@hotmail.com Orcid: https://orcid.org/0000-0003-1763-7799
} 


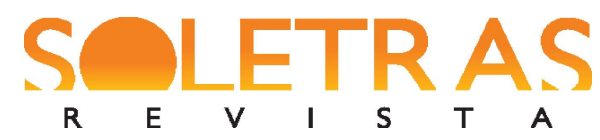

N. $40-2020.2$ - MARCUS VINICIUS NOGUEIRA SOARES

uso do aparato editorial de um periódico diário. José de Alencar aliou, assim, a edição de um jornal à criação de uma plataforma literária que permitiu a sua inserção no universo letrado, e não só jornalístico, de meados do século XIX. O presente artigo pretende analisar a importância desse empreendimento editorial para uma possível reinterpretação de sua produção inicial, especialmente romanesca, de José de Alencar. Para o desenvolvimento da análise, adotamos a perspectiva elaborada por Roger Chartier (1996) que lida com o texto em sua materialidade, considerando o entrecruzamento de dois diferentes dispositivos de produção de material escrito: os textuais, baseados em protocolos de leitura instituídos pelo autor no ato da escrita; e os de impressão que, oriundos de decisões editorias, orientam o modo como um texto pode ser lido por determinado público ao qual o produto impresso se destina. $^{2}$

\section{Na lide jornalística}

José de Alencar passou a atuar no jornalismo de forma sistemática quando, em setembro de 1854, ingressou no Correio Mercantil, assumindo a redação da série de folhetins "Ao correr da pena". ${ }^{3}$ Até então a sua produção tinha sido bastante dispersa, contabilizando três artigos, entre 1848 e 1850, no periódico Ensaios Literários, publicação vinculada à Faculdade de Direito de São Paulo, e, possivelmente, quatro folhetins da série "Álbum”, estampados no Diário do Rio de Janeiro entre julho e agosto de $1854 .{ }^{4}$ Publicada aos domingos, "Ao correr da pena" era parte integrante da seção de rodapé "Páginas menores", organizada por Francisco Otaviano, a qual ainda contava com a colaboração de Manuel Antônio de Almeida.

Pode-se dizer que foi com "Ao correr da pena" que Alencar ganhou certa notoriedade. Mesmo após a interrupção da série no Correio Mercantil, com a demissão, em julho de 1855, ela ainda repercutia nos periódicos da corte. Em agosto de 1855, O Correio da Tarde incorporou a voga da "revista semanal" com uma nova coluna intitulada "Ao voar da pena",

\footnotetext{
${ }^{2}$ Cumpre recordar que, no trabalho mencionado, Chartier (1996) lida apenas com a "produção de livros" (p. 95). Como a nossa abordagem envolve também periódicos, optamos pela expressão mais genérica "produção de material escrito".

${ }^{3}$ Alencar também escrevia na seção "O foro", voltada a assuntos jurídicos.

${ }^{4}$ A autoria da série é sustentada por Lira Neto (2006, p. 88-89).
} 


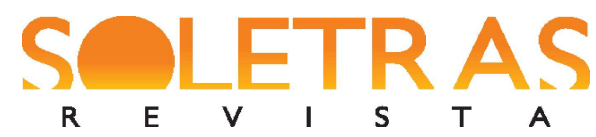

N. 40 - 2020.2 - MARCUS VINICIUS NOGUEIRA SOARES

remetendo ao "espírito diáfano e vaporoso do Correr da Pena" (AO VOAR..., 1855, p. 3). ${ }^{5}$ Nesse mesmo mês, o redator da Marmota Fluminense, na estreia de seu rodapé "Quinzena", assinalava:

\begin{abstract}
Não sei se vos agradarei, caras leitoras, pois além do pouco hábito que tenho de escrever para o público, acresce mais que vós deveis certamente estar acostumadas com a linguagem poética e amena do - Correr da pena do Dr. Alencar, - que é, sem dúvida alguma, um dos primeiros Folhetinistas desta capital, e por consequência dificilmente vos contentareis com outra linguagem. (QUINZENA, 1855, p. 1)
\end{abstract}

Essa boa repercussão permitiu que Alencar adentrasse de forma definitiva o campo jornalístico. E não demorou muito para que ele fosse, após a demissão, convocado a encabeçar o novo arranjo da empresa que administraria o Diário do Rio de Janeiro com a saída do então "diretor gerente", o comendador Luiz Navarro de Andrade. ${ }^{6}$ Dentre os principais acionistas, além do próprio escritor cearense, destacavam-se figuras eminentes do meio político da época, como o seu pai, o senador José de Alencar, o barão de Mauá, o visconde de Sapucaí, João Manuel Pereira da Silva e o conselheiro Luís Pedreira do Couto Ferraz. Alencar substituiria Navarro na função que comportava o trabalho tanto editorial quanto financeiro da folha, como se lê no texto de despedida de Navarro, apresentado na reunião em que os acionistas elegeram Alencar para o cargo:

A acertada escolha que acabais de fazer nomeando o Sr. Dr. José de Alencar redator em chefe do Diário e gerente da empresa, é a melhor prova que poderei dar de que aprecieis devidamente o talento e a inteligência. (RIO..., 1855, p. 1)

A mudança da diretriz editorial do Diário foi imediata e bastante significativa. No primeiro exemplar sob a nova gerência, em 6 de outubro de 1855, Alencar alterou o leiaute do

\footnotetext{
${ }^{5}$ Em todos os textos do século XIX, mantivemos a pontuação original, atualizando apenas a ortografia.

${ }^{6}$ Luiz Antônio Navarro de Andrade (1825-1909) foi, além de jornalista, cônsul e político. Ainda retornaria ao Diário por duas vezes: substituindo Alencar, em 1858, e depois entre dezembro de 1867 e abril de 1868, sempre como "redator em chefe".
} 


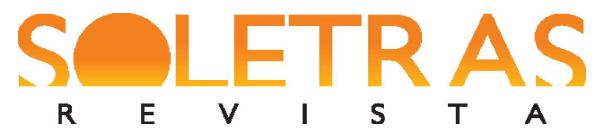

N. 40 - 2020.2 - MARCUS VINICIUS NOGUEIRA SOARES

jornal. Embora mantendo as mesmas sete colunas anteriores, procurou uma apresentação mais sóbria, diminuindo o tamanho dos tipos, o que permitiu um espaçamento maior entre as partes impressas na folha. Ao refazer o cabeçalho, retirou o brasão das Armas do Império do Brasil, que figurava em posição central entre as palavras do título. Manteve algumas colunas do formato anterior, muitas vezes com diferentes rubricas - "Corpo legislativo", por exemplo, que divulgava as sessões das assembleias, foi alterada para "Parte oficial" -, mas também criou novas, como "Folhas soltas", além de investir em artigos de fundo mais consistentes e assíduos - estes nem sempre apareciam nas edições sob a gerência de Navarro. Concedeu mais espaço à matéria comercial, que passou a ocupar metade de uma página. Retomou o folhetim, sem, contudo, dar continuidade ao romance que vinha sendo publicado anteriormente, no caso, Ingênua, de Alexandre Dumas, substituindo-o por Suzana, de Xavier de Montépin. Por fim, a contagem dos exemplares foi reiniciada, acompanhada da designação "2 2 série".

Nesse começo do novo empreendimento, podemos também assinalar a transformação ocorrida em novembro de 1855. Sem aviso prévio, Alencar reduziu o tamanho da folha do jornal pela metade, dobrou o número de páginas para oito e diminuiu a quantidade de colunas para quatro, tudo isso seguindo, de acordo com o editor, "um melhoramento imitado dos jornais ingleses" (AOS NOSSOS..., 1855, p. 1). Em abril de 1856, o jornal, com pequenas modificações, voltaria ao formato original, que seria mantido até o fim da gestão alencariana.

Ainda na esfera jornalística, já no segundo exemplar, em 7 de outubro de 1855, Alencar traria de volta, na seção "Folhetim", as crônicas de "Ao correr da pena": "correi, correi de novo, minha boa pena!” (ALENCAR, 1855, p. 1). No entanto, elas não foram além de sete exemplares, cessando em 25 de novembro, dando lugar, um mês depois da interrupção, ao "Livro do Domingo", só que agora redigido pelo seu irmão, Leonel de Alencar: "Venho substituir ao Correr da pena, e asseguro-vos que a substituição é a mais completa possível" (ALENCAR, L., 1855, p. 1). Entretanto, Alencar parecia ainda interessado na atividade de cronista. A partir de fevereiro de 1856, iniciou, às segundas-feiras, na seção de rodapé "Folhas soltas", outra série, intitulada "Conversa com os meus leitores", alternando o título para "minhas leitoras", de acordo com o assunto tratado. Na sequência, a série modificaria a rubrica, passando para "Folhetim", saindo também às quintas-feiras. Cada vez mais dispersa, ela se estenderia até dezembro do mesmo ano, contabilizando treze publicações. 


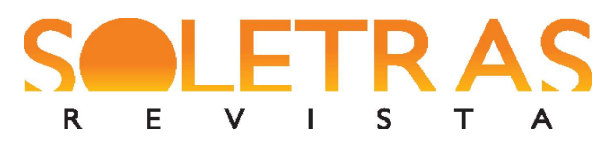

N. 40 - 2020.2 - MARCUS VINICIUS NOGUEIRA SOARES

Nos primeiros oito meses de trabalho, Alencar ocupou-se quase que exclusivamente com o campo jornalístico. Preocupado em conformar o mais antigo diário brasileiro em circulação a uma diretriz editorial diferenciada, o autor de Lucíola (1862) testou formatos, reajustou modalidades discursivas, objetivando a realização de um produto preponderantemente jornalístico. ${ }^{7}$ No entanto, demonstrou também interesse, especialmente a partir do final de 1855, por colunas relacionadas à esfera cultural. Ele dedicou à literatura uma seção de resenha de livros, "Revista bibliográfica", sob a responsabilidade de Augusto Emílio Zaluar, além de transcrever críticas literárias de outros periódicos, como as de $O$ Clarim Literário, escritas pelo poeta Pedro Calasans. Para as artes plásticas, criou a rubrica "Belas artes". Destinou ainda duas seções à dramaturgia, "Teatro lírico" e "Teatros", esta última assinada por Sousa Ferreira, isso sem contar as abordagens dramatúrgicas que frequentemente ocupavam boa parte dos folhetins hebdomadários que apareciam no rodapé da página. Com o passar do tempo, o interesse pela matéria cultural vai se desdobrando até adquirir contornos diferenciados em meados de 1856.

\section{Impressões de leitura: Alencar crítico}

Foi em junho de 1856 que José de Alencar estabeleceu novos parâmetros para o Diário. Em 19 do referido mês, veio a lume, na seção "Folhetim", a primeira carta sobre o tão aguardado poema épico de Gonçalves de Magalhães, A confederação dos Tamoios. Já se sabia da elaboração do poema pelo menos desde 1839, quando o primeiro canto saiu estampado na Revista Nacional e Estrangeira. ${ }^{8}$ Transcrevendo notícia de A Semana, jornal literário, científico e noticioso, o Diário comunicava, em dezembro de 1855, o aparecimento do livro, ricamente adornado, editado por Paula Brito, sob os auspícios do imperador Pedro II. ${ }^{9}$ Em 16 de junho de 1856, três dias antes da primeira carta, Alencar, fazendo os primeiros reparos ao poema a partir de trechos publicados na imprensa, destinou à obra todo o espaço do "Boletim do dia" - coluna que correspondia ao artigo de fundo -, uma vez que "o poema nacional do Sr. Magalhães está na ordem do dia; fala-se, ou lê-se, ou procura ler-se a Confederação dos

\footnotetext{
${ }^{7}$ O Diário do Rio de Janeiro foi fundado em 1821.

${ }^{8}$ Revista dirigida por Pedro de Alcântara Bellegarde, João M. Pereira da Silva e Josino do Nascimento Silva.

${ }^{9}$ No mesmo ano, houve uma outra edição do livro, financiada apenas pela empresa de Paula Brito.
} 


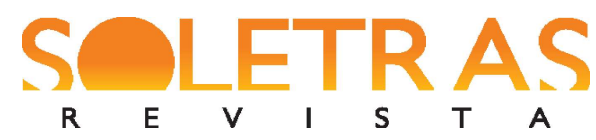

N. $40-2020.2$ - MARCUS VINICIUS NOGUEIRA SOARES

Tamoios" (BOLETIM..., 1856a, p. 1). No artigo, tratou brevemente de versos que não poderiam "estar no livro de um poeta como Sr. Magalhães" (BOLETIM..., 1856a, p. 1). Por sua vez, no mesmo dia, Leonel de Alencar, em seu "Livro do Domingo", repetiu o irmão, ressaltando, nos versos do poema, o "abuso de ditongos" e "das descrições" (ALENCAR, L., 1856, p. 1).

Em 17 de junho, o Diário publicava carta de Paula Brito reagindo à crítica alencariana. No "Boletim do dia" da mesma data, Alencar comentou a missiva e, na seção "Folhas soltas", o jornal publicou um trecho do poema, antecedido da seguinte observação: “Admira que não fosse citado esse belo pedaço, onde não se nota os defeitos de metrificação, que abundam nos trechos do poema que até agora se têm publicado" (CRÔNICA..., 1856a, p. 1). No dia seguinte, sob a rubrica "Comunicações”, apareceria uma carta não assinada, na qual o autor felicitava o Diário pelo seu posicionamento contrário à recepção favorável do poema que grassava em quase toda a imprensa da corte. Ao que tudo indica, antes mesmo da primeira carta que daria início à polêmica, Alencar teria percebido o alcance público do embate e resolveu assumi-lo.

Assim, com o pseudônimo Ig., o autor de Iracema encetaria, a partir de 19 de junho de 1856, várias considerações sobre o poema, inaugurando uma polêmica que contou com a participação de figuras ilustres do mundo letrado de então, como Araújo Porto-Alegre, frei Francisco do Monte Alverne e o imperador Dom Pedro II, que se manifestaram também pelos jornais, como o Correio da Tarde e o Jornal do Commercio. ${ }^{10}$ Alencar utilizou o expediente de cartas remetidas por um suposto amigo do próprio editor do Diário, como se lê no "Boletim do dia": "Publicamos no folhetim uma carta de um nosso amigo que nos comunica as impressões de sua leitura sobre o novo poema do Sr. Magalhães” (BOLETIM..., 1856b, p. 1). A crítica se prolongaria até agosto, quando o autor imprimiu a oitava carta e mais dois artigos na seção "Folhas soltas". Meses depois, o conjunto epistolar sairia em livro pela Empresa Tipográfica Nacional do Diário com a seguinte intitulação: Cartas sobre $A$ confederação dos Tamoios, por Ig (Publicadas no Diário). ${ }^{11}$ Foi quando Alencar finalmente assumiu a autoria:

\footnotetext{
${ }^{10}$ Monte Alverne só ingressaria no debate em 23 de dezembro de 1856, quando o Jornal do Commercio publicou o seu texto, que seria logo transcrito pelo Diário do Rio de Janeiro nos dois dias seguintes. Ou seja, a sua entrada em cena somente se deu após o encerramento da polêmica e com o livro de Alencar já publicado.

${ }^{11}$ Segundo nota no Diário, o responsável pela edição foi Antônio Maria Navarro de Andrade, antigo proprietário e ainda sócio da empresa do jornal.
} 


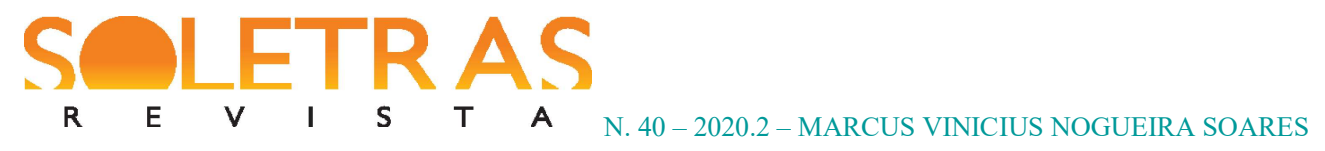

Ocultei a princípio o meu nome, não pelo receio de tomar a responsabilidade do escrito; e sim porque obscuro como é, não daria o menor valor às ideias que emiti. Desde, porém, que a crítica das colunas de um jornal passa às folhas de um livro, entendo que é dever de lealdade para com o poeta que censurei, e para com o público que me serviu de juiz, assinar aquilo que escrevi. (ALENCAR, 1856a, p. 1)

Há dois aspectos que gostaríamos de pontuar concernentes à polêmica empreendida por Alencar. O primeiro diz respeito ao fato de que, durante o debate, o seu nome não foi aventado como possível autor das cartas, a despeito dos indícios deixados por ele nos textos, já aqui referidos, impressos nos exemplares que antecederam a série de artigos. Talvez isso possa ser creditado à sua intensa atividade jornalística, que, até aquele momento, parecia ser a única em que ele publicamente se destacava. O segundo aspecto alude à importância cultural da polêmica, uma vez que não se tratava apenas de investir contra o laureado Magalhães e seu poema épico, mas sim da possibilidade de fazê-lo, legitimado pelo anacronismo da proposta literária do autor dos Suspiros poéticos e saudades: escrever uma epopeia em pleno século da poesia lírica e do romance. Apesar de Alencar ter utilizado muitas vezes em suas apreciações formais do poema exemplos da épica do passado, como os de Homero, Virgílio, Milton e Basílio da Gama, e de ter tentado uma epopeia alguns anos depois, como veremos mais adiante, o seu escopo crítico foi pautado fundamentalmente pelas obras de escritores oitocentistas como Chateaubriand, Lamartine e Walter Scott. ${ }^{12} \mathrm{O}$ autor de Iracema estava alinhado com uma nova geração, da qual faziam parte Álvares de Azevedo e Bernardo Guimarães, que, na década de 1850, começava a questionar padrões literários seguidos pelos primeiros românticos brasileiros, como Gonçalves de Magalhães, Araújo Porto-Alegre, João Manuel Pereira da Silva, entre outros. Não se tratava apenas de atacar um poeta de reputação, mas também de demonstrar o desajuste de uma obra em face das novas concepções de arte e literatura que ganhavam corpo em meados do século XIX.

Em 4 de setembro de 1856, um dia após o falecimento de Honório Hermeto Carneiro Leão, o marquês de Paraná, Alencar principiou um esboço biográfico que prosseguiu em mais

\footnotetext{
12 Vale lembrar que, em junho de 1856, Alencar havia iniciado uma campanha de subscrição para o Curso familiar de literatura, de Lamartine, com intuito de ajudar o poeta francês que passava dificuldades financeiras. A lista de subscritores contou com a contribuição de Pedro II, que ainda acrescentou à sua assinatura a seguinte frase: "Les siècles sont à toi, l'univers est ta patrie”" (BOLETIM..., 1856c, p. 1).
} 


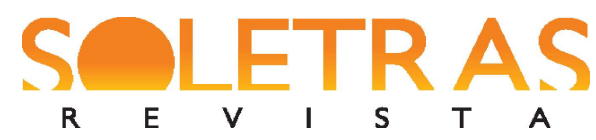

N. $40-2020.2$ - MARCUS VINICIUS NOGUEIRA SOARES

três exemplares até o dia 7 do mesmo mês. Tal como as cartas sobre $A$ confederação dos Tamoios, o texto seria também editado em livro pela mesma tipografia com o título $O$ marquês de Paraná. Traços biográficos (Publicados no Diário). Ambos os livros foram lançados em novembro de 1856 e contaram com boa divulgação na seção de anúncios do jornal - prática usual na imprensa da época, que Navarro utilizou largamente em sua gestão. Em pouco mais de um ano de gerência editorial de uma folha diária, Alencar se tornara autor de duas obras, inscrevendo-se no mercado editorial e dando assim início à sua trajetória literária. $^{13}$

\section{Na lide literária: Alencar romancista}

É possível que a repercussão de sua intervenção crítica tenha estimulado Alencar a investir mais no projeto de editoração literária. E não se trata aqui de estabelecer a relação, que a fortuna crítica do autor comumente faz, entre a polêmica sobre $A$ confederação dos Tamoios e $O$ guarani, como se este romance tivesse sido a resposta alencariana ao fracasso por ele assinalado na obra de Magalhães. Segundo essa perspectiva, Alencar, ao demonstrar com $O$ guarani a funcionalidade extemporânea da poesia épica, promoveu o romance à posição de gênero capaz de realizar a nacionalização da literatura. Entretanto, é importante recordar que Alencar tentou, em 1863, a epopeia, rabiscando um longo poema em doze cantos, "Os filhos de Tupã", que só chegou a cinco, sendo que os dois últimos ficaram incompletos. $\mathrm{O}$ autor fez menção a essa tentativa em carta endereçada ao dr. Jaguaribe, impressa ao final da primeira edição de Iracema, lenda do Ceará (1865). Depois de relembrar o que escrevera na polêmica sobre $A$ confederação dos Tamoios a respeito da possível elaboração de um poema de matéria indígena, Alencar ponderou:

Tanto bastou para que supusessem que o escritor se referia a si, e tinha já o poema em mão; várias pessoas perguntaram-me por ele. Meteu-me isto em brios literários; sem calcular das forças mínimas para empresa tão grande que assoberbou dois ilustres poetas, tracei o plano da obra, e a comecei com

\footnotetext{
13 Talvez por um lapso de memória, Alencar, em Como e porque sou romancista, concedeu a Cinco minutos a primazia nessa trajetória: "[ao final de 1856] saiu um romancete, meu primeiro livro, se tal nome cabe a um folheto de 60 páginas” (ALENCAR, 1893, p. 42).
} 
tal vigor que levei quase de um fôlego ao quarto canto. ${ }^{14}$ (ALENCAR, 1865, p. 193)

Mais adiante, como a carta tinha a pretensão de "contar como e porque escrevi Iracema" (ALENCAR, 1865, p. 200), Alencar apresentaria as razões que o levaram a optar, diante da dificuldade de escrita e da insatisfação com os versos até então produzidos, pelo tipo de prosa que resultou neste seu romance:

Em um desses volveres do espírito à obra começada, lembrou-me de fazer uma experiência in anima prosaica. $\mathrm{O}$ verso pela sua dignidade e nobreza não comporta certa flexibilidade de expressão que, entretanto, não vai mal à prosa mais elevada. A elasticidade da frase permitiria então que se empregassem com mais clareza as imagens indígenas, de modo a não passarem desapercebidas. Por outro lado, conhecer-se-ia o efeito que havia de ter o verso pelo efeito que tivesse a prosa. (ALENCAR, 1865, p. 199)

Se $O$ guarani fosse a resposta imaginada à polêmica, caberia então a pergunta sobre um possível descontentamento de Alencar com o resultado de seu romance, já que ainda insistiria, cinco anos depois, na composição de uma epopeia. Na verdade, essa resposta foi adiada até a escrita de Iracema. Considerando a transformação que se operou entre "Os filhos de Tupã" e a "lenda" de 1865, pode-se dizer que Alencar não desdenhou por completo a poesia épica. O que o incomodou no poema de Magalhães foi a utilização da epopeia em um relato no qual preponderava o prosaísmo formal e temático mais afeito ao romance histórico. Talvez a matéria do poema funcionasse melhor se fosse tratada em prosa por Walter Scott:

Estou bem persuadido que se Walter Scott traduzisse esses versos portugueses no seu estilo elegante e correto; se fizesse desse poema um romance, dar-lhe-ia um encanto e um interesse que obrigariam o leitor que folheasse as primeiras páginas do livro a lê-lo com prazer e curiosidade. (ALENCAR, 1856a, p. 57)

\footnotetext{
14 Alencar menciona quatro cantos, mas, afora uns trechos avulsos, seriam cinco, conforme texto publicado na edição da Aguilar de 1959, transcrito do acervo dos manuscritos do autor. 


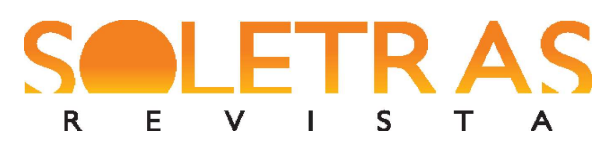

N. 40 - 2020.2 - MARCUS VINICIUS NOGUEIRA SOARES

Assim, com a produção scottiana, a matéria histórica teria migrado para o romance, deixando para a epopeia o primitivismo mítico e lendário que Alencar resgatou, fundindo-o com a prosa de Iracema. Não foi à toa que, mais tarde, o autor não dispôs $O$ guarani ao lado de Iracema, quando refletia sobre a sua produção no afamado prefácio ao Sonhos d'ouro (1872), intitulado "Bênção paterna": enquanto o primeiro vinculava-se à fase "histórica", juntamente com Minas de prata (1865-66), o segundo enquadrava-se na "primitiva" (ALENCAR, 1872, p. XIII) - rubrica sob a qual provavelmente estaria Ubirajara, se não tivesse sido impresso dois anos após o prefácio.

Apesar de toda a discussão envolvendo a nacionalidade literária que se viu na polêmica, Alencar parecia, nesse primeiro estágio de sua carreira, mais interessado em uma empreitada editorial, inclusive de sua própria obra, do que na gestação convicta de um projeto de consecução de uma literatura genuinamente nacional, como ficou consagrado na historiografia literária. Como o entendemos, esse projeto só poderia ser pensado a partir de meados da década de 1860, quando "Os filhos de Tupã" se transformou em Iracema, mantendo, contudo, o lastro épico. Além disso, entre a polêmica e $O$ guarani, apareceu Cinco minutos, um romance urbano sentimental, entremeado por peripécias.

Foi ao final de 1856, em sete exemplares entre 22 e 30 de dezembro, que Alencar publicou, na seção "Folhetim", Cinco minutos. Na data de estreia, na coluna "Crônica diária", anunciava-se a publicação:

Começamos a publicar hoje no folhetim um pequeno romance original, que nos foi confiado por alguém que deseja ocultar o seu nome, e que recomendamos à benevolência do leitor como um ligeiro ensaio. Durante os dias que fizermos esta publicação, o nosso folhetim ordinário será impresso no verso da página. (CRÔNICA...,1856b, p. 1)

Além da menção ao "folhetim ordinário", que no caso tratava-se de $O$ acendedor de lampiões, romance de 1854 da escritora norte-americana Maria Susanna Cummins, que vinha sendo publicado desde setembro, vale destacar no trecho citado o expediente de ocultação da autoria; ou seja, o texto que foi supostamente entregue por alguém que não pertencia ao quadro de redatores do jornal, eximindo-os ficcionalmente da responsabilidade autoral do romance, algo semelhante ao que ocorrera nas cartas da polêmica, embora lá constasse um 


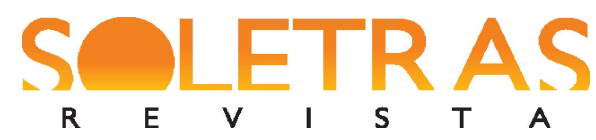

N. 40 - 2020.2 - MARCUS VINICIUS NOGUEIRA SOARES

pseudônimo. Cinco minutos apareceu, assim, sem assinatura, com o texto disposto no rodapé da página com título, rubrica (romance) e dedicatória endereçada a uma prima cuja primeira letra do nome era $\mathrm{D}^{* * *}{ }^{15}$ Esta prima era também a interlocutora para quem o narrador relatava a sua história em forma de carta: "É uma história curiosa a que lhe vou contar, minha prima. Mas é uma história, e não um romance” (ALENCAR, 1856b, p. 1). Ou ainda: “Adeus, minha prima; Carlota impacienta-se porque há muitas horas que lhe escrevo. Não quero que ela tenha ciúmes desta carta, e que me prive de enviá-la" (ALENCAR, 1856d, p. 1). O enredo se desenrolava nas ruas e salões do Rio de Janeiro, com pequenas incursões por Petrópolis e Itália. Ao término da publicação, o romance ganharia a forma de livro e, mais uma vez, impresso pela tipografia do Diário. Entretanto, diferentemente dos outros dois volumes de Alencar, Cinco minutos teria uma primeira edição exclusivamente tirada para presentear os assinantes, como se lê em nota estampada na data do último capítulo, 30 de dezembro:

Desejando mostrar o apreço em que tem as suas leitoras, oferecendo-lhes também o seu presente de ano bom, o Diário fez tirar em um pequeno volume o romance cuja publicação acaba hoje, e que tem por título Cinco minutos, para distribuir pelos seus assinantes no $1^{\circ}$ de janeiro. Espera, pois, que tenham a bondade de mandar recebê-lo naquele dia e nos seguintes no escritório desta folha; e pede-lhes desculpa pelo nenhum valor do presente, que só tem o merecimento de ter sido dedicado às suas leitoras (CRÔNICA...,1856c, p. 1)

Durante o período em que Cinco minutos foi divulgado, o jornal publicou outros dois romances: O marquês de Pombal, de Clémence Robert, na seção "Folhas soltas", e o já referido $O$ acendedor de lampiões, de Maria Cummins, no "Folhetim". Desse modo, Alencar não deixava de seguir o procedimento padrão da imprensa da época, que consistia na difusão significativa de romances de diversos países, especialmente da França. Contudo, ganha destaque a quantidade de espaço consumido simultaneamente pelos romances no Diário, se compararmos com o volume de publicações em cada grande jornal que circulava no final de 1856: dois no Correio da Tarde e apenas um tanto no Jornal do Commercio quanto no Correio Mercantil. Ademais, o projeto editorial adquiria cada vez mais consistência, pois, em

\footnotetext{
${ }^{15}$ Transcrevemos os asteriscos como aparecem nos originais de Cinco minutos e $O$ guarani. Eles não constam de A viuvinha.
} 


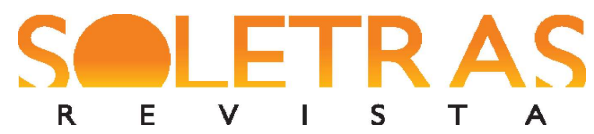

N. $40-2020.2$ - MARCUS VINICIUS NOGUEIRA SOARES

17 de fevereiro de 1857, noticiava-se o lançamento próximo da segunda edição de Cinco minutos em um anúncio cujo título era "Biblioteca do Diário". A lista incluía ainda os livros sobre o marquês de Pombal, as cartas da polêmica e, no prelo, as duas primeiras partes de $O$ guarani, além do romance de Clémence Robert. A listagem, sob a mesma rubrica, reapareceria ao final do quarto volume de $O$ guarani, mas sem o livro de Robert.

Se houve algum projeto minimamente organizado nos primórdios da carreira de José de Alencar, podemos creditá-lo a essa tentativa de realização da "Biblioteca do Diário" que, direcionada, embora não restrita, à própria obra alencariana, correspondia ao início da configuração editorial de uma trajetória literária. Por esse prisma, O guarani seria mais uma etapa desse percurso.

\section{Trilogia do Diário}

Iniciado em $1^{\circ}$ de janeiro e concluído em 20 de abril de 1857, O guarani faria parte, ao lado de Cinco minutos e $A$ Viuvinha, de uma espécie de trilogia literária. A conformação entre os três romances só se torna perceptível quando os confrontamos nas publicações periódicas; ela não se mantém integralmente nas edições em livro.

O primeiro elo entre os romances foi dado pelo Diário do Rio de Janeiro em 31 de dezembro de 1856, um dia antes do início de $O$ guarani: "o autor do romance que ontem terminamos, enviou-nos outro que começamos a publicar amanhã” (CRÔNICA..., 1856d, p. 1). Aviso necessário, uma vez que ambos os textos não foram assinados. Além disso, o modo epistolar de Cinco minutos reapareceria em $O$ guarani, que trazia a mesma dedicatória a $\mathrm{D}^{* * *}$ e igualmente a tratava como interlocutora. Todavia, diferentemente do que ocorreu em Cinco minutos, no qual as marcas interlocutórias integravam o corpo do texto, em $O$ guarani, elas ficaram à margem, fixadas nos paratextos como o prólogo e as notas de rodapé.

No capítulo IV de Cinco minutos, divulgado em 23 dezembro de 1856, o narrador, depois de tanto procurar na corte pela misteriosa dama que conheceu no ônibus do Andaraí, estava em Petrópolis, em frente à casa onde provavelmente a jovem se encontrava. Para que ela soubesse de sua presença, ele começou a cantar um dos trechos de Il Trovatore, de Verdi, ópera que desde o início do romance servia de vínculo entre os dois personagens. A jovem imediatamente lhe respondeu cantando a mesma melodia. Escreveu o narrador: "Oh! não 


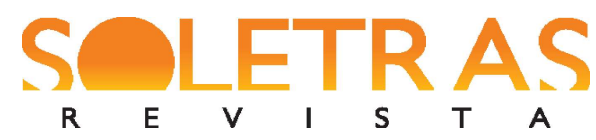

N. 40 - 2020.2 - MARCUS VINICIUS NOGUEIRA SOARES

posso pintar-lhe, minha prima, a expressão profundamente triste, a angústia de que ela repassou aquela frase de despedida: Non ti scordar di me, Addio!" (ALENCAR, 1856c, p. 1). O contato foi interrompido e o narrador resolveu permanecer ali por mais um tempo: "não se ria, D***; estava resolvido a passar ali a noite, ao relento, olhando para aquela casa, e alimentando a esperança de que ela viria ao menos compensar o meu sacrifício com uma palavra" (ALENCAR, 1856c, p. 1). Como se pode perceber pelas passagens citadas, a menção tanto ao laço de parentesco quanto à letra inicial do nome ocorreu no corpo do texto, como elemento funcional de uma narrativa que se pretendia epistolar.

Já em O guarani, além da dedicatória, a prima apareceria no prólogo: "Minha prima. Gostou da minha história, e pede-me um romance; acha que posso fazer alguma coisa neste ramo de literatura" (ALENCAR, 1857a, p. 1). Contudo, no mesmo prólogo, o autor assinalava que não se tratava de uma obra própria, mas sim o resultado do trabalho de transcrição de um manuscrito encontrado por ele e Carlota, a jovem com quem ele havia se casado em Cinco minutos. A interlocução ainda vai se manifestar nas notas, mais propriamente em uma nota vinculada ao capítulo XIV da primeira parte (o romance foi divido em quatro). A cena correspondia ao momento em que o narrador assinalava o interesse de Peri em perseguir uma índia Aimoré que sobrevivera após seus familiares serem mortos por Diogo de Mariz e pelo próprio Peri. Este deduziu que a jovem comunicaria à sua tribo o que ocorrera, motivando a vinda dos Aimorés com intuito de vingar a morte de seus membros:

Ora, o índio conhecia a ferocidade desse povo sem pátria e sem religião, que se alimenta de carne humana e vive como feras no chão pelas grutas e cavernas; estremecia só com a ideia de que pudesse vir assaltar a casa de D. Antônio de Mariz. (ALENCAR, 1857b, p. 1).

Com um sinal de asteriscos ao fim desse parágrafo, o autor remetia o leitor ao rodapé da quinta coluna do folhetim, no qual se encontrava a seguinte nota: "O manuscrito que estou copiando, tem a data de 1758; por isso não se admire que o autor fale no presente. Hoje não existem Aimorés, minha prima” (ALENCAR, 1857b, p. 1). Em nenhuma outra ocasião da narrativa a interlocução reapareceria. A voz que enunciava a narrativa de $O$ guarani não coincidia com a de Cinco minutos. O trabalho do marido de Carlota foi então o de transcrever 
o manuscrito encontrado e, semelhante a um copista medieval, anotá-lo com observações marginais. $\mathrm{O}$ enquadramento epistolar de Cinco minutos foi assim mantido em $O$ guarani por intermédio do envio das transcrições à mesma destinatária, mas não porque o texto da narrativa correspondesse à escrita de uma carta enviada.

Abordemos agora $A$ viuvinha como parte integrante da trilogia. Em 21 de abril de 1857, no dia seguinte ao encerramento de $O$ guarani, iniciava-se mais um romance em que D. despontava como destinatária e interlocutora da narrativa:

Se passasse há dez anos pela praia da Glória, minha prima, antes que as novas ruas que se abriram tivessem dado um ar de cidade às lindas encostas do morro de Santa Teresa, veria de longe sorrir-lhe entre o arvoredo, na quebrada da montanha uma casinha alva de quatro janelas com um pequeno jardim na frente (ALENCAR, 1857e, p. 1).

O narrador era o mesmo de Cinco minutos, com a diferença que ele não relatava a sua própria história, e sim a de um casal, Jorge e Carolina, que tinha vivenciado contratempos amorosos às vésperas do casamento.

O problema é que não sabemos ao certo como essa trilogia se concretizaria, pois, a publicação de $A$ viuvinha foi interrompida sem qualquer esclarecimento por parte de Alencar. O romance teve doze capítulos veiculados em seis diferentes exemplares do jornal, o último em 29 de junho de 1857. Percebe-se que o tempo foi longo para a pouca quantidade de material publicado - setenta dias entre a primeira e última aparições. O texto teve longas interrupções: a primeira, entre 26 de abril e 18 de maio; e a segunda, entre 18 de maio e 29 de junho. No interregno da primeira, em 14 de maio, o jornal chegou a publicar um aviso:

Estamos em uma grande falta para com os nossos leitores por causa da interrupção do folhetim. A falta, porém, é involuntária; e amanhã continuaremos a publicação para terminá-lo sem mais interrupções. (CRÔNICA..., 1857, p. 1).

A retomada, como vimos, não seria no dia 15, mas apenas no dia 18 , e paralisando mais uma vez durante 36 dias. 


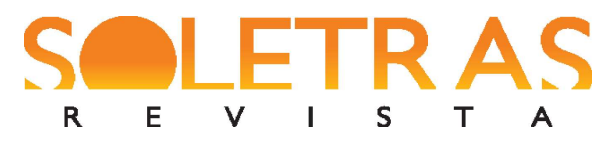

N. 40 - 2020.2 - MARCUS VINICIUS NOGUEIRA SOARES

Em Como e porque sou romancista, escrito em 1873, mas só divulgado em 1893, Alencar apresentaria uma versão para a interrupção de $A$ viuvinha. Lá ele explicava que Leonel de Alencar lhe solicitara um texto para o seu "Livro do Domingo". O autor de Iracema permitiu ao irmão que pegasse um rascunho qualquer em sua mesa de trabalho e o publicasse. Leonel acabou se valendo do que seria a continuação de $A$ viuvinha e estampado em seu folhetim semanal. Apesar de ser o redator em chefe do jornal, Alencar, "fatigado do trabalho da véspera, urgido pelas ocupações do dia, em constantes tribulações", não chegou a "passar os olhos por toda a folha" (ALENCAR, 1893, p. 43), razão pela qual não leu o artigo daquela data. Com a continuação antecipada da narrativa, Alencar acabou abandonando o romance.

A despeito da facticidade do relato alencariano, o que importa aqui assinalar é que $A$ viuvinha só teria prosseguimento quando saiu em livro, em 1860, dividindo o volume com a terceira edição de Cinco minutos. Neste momento, a conjunção dos dois romances corroboraria o definitivo afastamento editorial de $O$ guarani da suposta trilogia; corroboraria, pois, na edição impressa pela tipografia do Diário, em 1857, ambos, prólogo e nota, já tinham desaparecido, eliminando por completo a interlocução inicialmente estabelecida. Em livro, $O$ guarani ganhou autonomia, sem que nenhum traço material o conectasse aos outros dois romances, o que acabou sendo atestado pelo livro de 1860.

Uma nova conexão de $O$ guarani seria depois estabelecida com outro romance do autor, As minas de prata. Com intuito de sugerir uma possibilidade renovada de leitura da história de Peri e Ceci, façamos um breve contraponto entre as duas obras a partir do famoso final do romance de 1857.

Como se sabe, $O$ guarani foi dividido em quatro partes, cada qual subdividida em capítulos numerados e acompanhados de títulos. A exceção ficou por conta do "Epílogo" que, embora estivesse sob a rubrica "Quarta parte”, deu início a uma nova contagem de capítulos não titulados - cinco no total. Com uma chamada em letras garrafais, o "Epílogo" foi distribuído em cinco datas distintas: 12, 16, 17, 18 e 20 de abril de 1857. Tanto o aparato gráfico quanto a recontagem concediam um grande destaque a esse novo estágio da narrativa. Isso fica mais evidente quando o comparamos com o capítulo anterior, o décimo da quarta parte, intitulado "O cristão", estampado em 9 de abril, em que se narrava o incêndio do solar que levou à morte de quase todos os personagens da história, excetuando Peri, Ceci e d. Diogo de Mariz - este tinha viajado ao Rio de Janeiro. De fato, este capítulo encerrava o conflito no qual o romance estava baseado, ou seja, a proximidade de um ataque dos Aimorés com intuito 


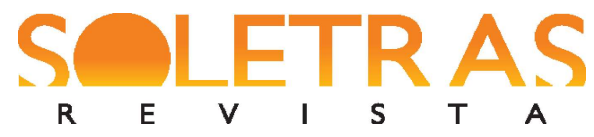

N. $40-2020.2$ - MARCUS VINICIUS NOGUEIRA SOARES

de vingar o assassinato de um membro da tribo cometido por d. Diogo de Mariz. O final do capítulo parecia até mesmo sugerir o término do romance:

As trevas envolveram o rochedo há pouco esclarecido pelas chamas; e tudo entrou de novo no silêncio profundo da noite.

Um soluço partiu o peito de Peri; talvez a única testemunha dessa grande catástrofe.

O índio dominando a sua dor, vergou-se sobre o remo, e a canoa voou sobre a face lisa e pálida do Paquequer. (ALENCAR, 1857c, p. 1, grifo do autor).

Todavia, não foi o que ocorreu. Três dias depois, apareceria o "Epílogo", dando sequência à narrativa de Peri e Ceci descendo o rio. Considerando tudo que foi relatado até o capítulo anterior, nenhuma informação foi acrescentada, uma vez que não se tratava de uma seção que solucionasse conflitos ainda pendentes. Na verdade, o "Epílogo" instaurou dois novos conflitos que pareciam iniciar um outro romance: o primeiro estava relacionado à decisão do rumo a ser tomado pelos dois personagens, o Rio de Janeiro ou a aldeia dos Goitacazes; o segundo, ao como sobreviver a uma provável enchente do rio. Este conflito foi resolvido com o famoso gesto heroico de Peri arrancando do solo uma palmeira que, utilizada como uma embarcação, permitiu ao casal continuar a fuga pelo rio; já aquele ficou em aberto: "A palmeira arrastada pela torrente impetuosa correndo com uma rapidez vertiginosa desapareceu no horizonte" (ALENCAR, 1857d, p. 1).

Por conta deste final, $O$ guarani é geralmente interpretado como um romance de formação, uma vez que postula miticamente o surgimento da nacionalidade brasileira. Como sintetizou Coelho Neto, no discurso de inauguração da estátua de José de Alencar em 1897, tratava-se da "conjugação dos dois espíritos: o do índio, Peri, o mundo selvagem, com o de Ceci, a Civilização. [...] Eis a vida inicial da Pátria" (NETO, 1897, p. 1). ${ }^{16}$ Em 1862, com o subtítulo "continuação do Guarani”, Alencar publicaria dois volumes de As minas de prata pela "Biblioteca Brasileira" do Diário do Rio Janeiro, mas foi só entre 1865 e 1866 que o texto saiu completo, em seis volumes, pela editora Garnier. O romance narrava a busca de Estácio Correia pelo roteiro das minas de prata de seu pai, o aventureiro Robério Dias. Se, em O guarani, o roteiro estava em poder do vilão Loredano, em As minas de prata, ele se

${ }^{16}$ Em 28 de abril de 1929, comemorando o centenário de nascimento de José de Alencar, o Jornal do Brasil republicou esse texto de Coelho Neto. 


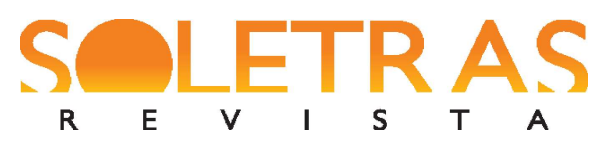

N. $40-2020.2$ - MARCUS VINICIUS NOGUEIRA SOARES

encontrava sob os cuidados de d. Diogo de Mariz, que o descobriu no meio dos escombros do solar, quando regressara do Rio de Janeiro depois da catástrofe. No primeiro capítulo da terceira parte, depois de mencionar a dor do jovem fidalgo com a perda "de um só golpe de toda a família" (ALENCAR, 1866, p. 6), o narrador descreveu a sala onde ele aguardava a visita de outro personagem que também tentava se apossar do roteiro, o padre Gusmão de Molina:

\begin{abstract}
A sala em que se achava o fidalgo era como a pagina desdobrada do íntimo de sua alma: ali estavam em torno, a cingi-lo, as recordações mais palpitantes de sua vida. Os retratos de seus pais, de Cecília e Isabel pendiam das paredes; e em frente à papeleira onde escrevia, um pintor do tempo imaginara sob as indicações do fidalgo uma cópia muito semelhante da casa do Paquequer, assentada sobre o rochedo à margem do rio. A um lado via-se uma palhoça, e encaminhando-se a ela um índio que figurava Peri: no terreiro D. Antônio passeando com um mancebo fidalgo que representava Álvaro de Sá. (ALENCAR, 1866, p. 6-7).
\end{abstract}

Considerando os seis volumes de As minas de prata, este é o único momento em que os nomes de Ceci e Peri são mencionados. Para Alencar, a continuação de $O$ guarani correspondeu a uma sequência do que ocorreu a partir das ruínas de um empreendimento colonial fracassado - a comunidade construída por d. Antônio de Mariz em torno do solar -, e não pelo que teria acontecido ao casal após descer o rio. $\mathrm{O}$ desconhecimento do destino dos dois personagens por parte de d. Diogo nos permite aventar a hipótese de que o rumo tomado pelo casal não teria sido a cidade do Rio de Janeiro, mas sim a aldeia dos Goitacazes. Nesse sentido, ao invés de se constituir em princípio mítico do processo de formação nacional, o "Epílogo" daria início a um processo de aculturação que, caracterizado pela absorção do elemento europeu pelo aborígene, quase não teria deixado lastro histórico.

\title{
Nos palcos da corte: Alencar dramaturgo
}

No segundo semestre de 1857, Alencar se dedicaria com afinco ao teatro. Em outubro, ele teria a sua primeira peça, Rio de Janeiro, verso e reverso, encenada no teatro Ginásio 
Dramático. Ainda nesse mês, nos dias 26 e 27, publicaria, nas páginas do Diário, o libreto de ópera cômica intitulado $A$ noite de S. João, com a seguinte recomendação:

Finalmente, tendo sido o meu desejo, escrevendo isto, somente o ver uma ópera nacional de assunto e música brasileira, cedo de bom grado todos os meus direitos de autor àquele que a puser em música o mais breve possível (ALENCAR, 1857f, p. 1).

O desejo de Alencar foi realizado por Elias Álvares Lobo, que musicou o libreto e encenou a ópera em 1860, tendo o jovem Carlos Gomes como regente da orquestra. Em novembro de 1857, estrearia a peça alencariana de maior sucesso, $O$ demônio familiar. Em dezembro, seria a vez de $O$ crédito, que teve apenas três récitas. A noite de S. João bem como Rio de Janeiro, verso e reverso foram impressas pela tipografia do Diário. O que poderia corresponder apenas a uma atividade externa àquela desempenhada por Alencar no jornal encontrava mais uma vez respaldo dentro de um projeto que era, ao mesmo tempo, jornalístico e editorial. No caso de $O$ demônio familiar, que acabou só saindo em livro após o afastamento de Alencar do Diário, em 1858, caberia acrescentar a percepção de uma dinâmica cultural mais intensa, pois a sua encenação suscitou diversas intervenções críticas tanto no Diário quanto em outros jornais da corte, contudo sem provocar nenhum debate acalorado.

No entanto, foi com a sua quarta peça, As asas de um anjo, que Alencar se viu mais uma vez às voltas com uma polêmica. Na reabertura do Teatro Ginásio Dramático após uma reforma, em 30 de maio de 1858, aconteceria a primeira récita da peça, cuja performance era acompanhada, no intervalo entre o prólogo e o primeiro ato, pela apresentação de uma polca zarzuela de mesmo nome, composta por Antônio de Assis Asternold. De acordo com um assinante do Correio Mercantil, a estreia teve boa procura, "às 7 horas já estava o pequeno saguão apinhado de espectadores à espera que se abrisse a porta das cadeiras" (REVISTA..., 1858, p. 2), e ainda contou com a presença de Suas Majestades Imperiais. A segunda récita se deu no dia $1^{\circ}$ de junho. Nove dias depois, na seção "Crônica diária", sairia a seguinte nota:

Algumas pessoas têm-se incumbido de espalhar que a polícia proibiu a representação da comédia $A s$ asas de um anjo; e esta notícia tem sido 


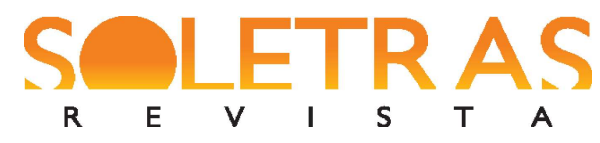

acreditada. Podemos, porém, asseverar que tal fato não se deu, e que semelhante proibição não existe. (CRÔNICA..., 1858a, p. 1)

De fato, a comédia de Alencar não foi interrompida pela polícia naquela ocasião, pois, em 17 de junho, aconteceria, finalmente, a terceira récita e, na mesma seção do jornal, apareceria um novo aviso:

Vai hoje à cena a comédia original As asas de um anjo, cuja representação foi interrompida pela moléstia de um ator. Os juízos vários encontrados que se tem feito a respeito desta peça podem hoje ser devidamente apreciados pelo público; ele dirá se há razão da parte daqueles que condenam o autor por ter querido imitar a escola realista, atualmente tão em voga na França. (CRÔNICA..., 1858b, p. 1)

É interessante sublinhar que, na primeira nota, quando a peça se encontrava suspensa por quase dez dias, não havia menção à doença do ator, mas somente a um boato sobre a intervenção policial. Já na segunda, a doença foi assinalada, e, embora nada tenha sido dito a respeito de qualquer ação da polícia, o redator apressou-se em defender a peça de juízos condenatórios que, ao que tudo indica, corriam de boca em boca pelo menos desde a récita anterior. No dia 21 de junho, As asas de um anjo foi definitivamente impedida de ser encenada por ordem do chefe de polícia Isidoro Borges Monteiro. Em resposta, Alencar publicou, em 23 de junho, um trecho da ordem judicial assim como um longo artigo no qual defende a peça de suposta imoralidade. Um breve debate se instaurou, inclusive em outros jornais.

José de Alencar, que desde de abril de 1857 passou a ser apenas "redator em chefe", e, a partir de novembro do mesmo ano, dividiu a direção do jornal com J. F. Lopes Anjo, nomeado "diretor da empresa", abandonou a folha um mês após a breve e conturbada encenação de As asas de um anjo. Sem carta de despedida, Alencar provavelmente levou consigo toda a sua obra, pois, desde então, ela desapareceu da propaganda do jornal, não obstante os livros de outros autores por ele editados continuarem sendo anunciados, como os romances Marta, de Max Valrey, Sofia Printems, de Alexandre Dumas Filho, o já mencionado $O$ marquês de Pombal, de Clemence Robert, a obra historiográfica Exposição 
histórica da maçonaria no Brasil, de Manuel Joaquim de Menezes, e os Anais do parlamento brasileiro: Senado.

\section{Considerações finais}

De imediato, é possível dizer que, no Brasil do século XIX, considerando as condições materiais de produção literária do período, o fato de um escritor encontrar-se vinculado a um jornal, publicando os seus textos ficcionais ou colaborando com artigos mais propriamente jornalísticos, não seria representativo de um traço diferencial de sua atividade, uma vez que grande parte dos que escreviam nessa época estava direta ou indiretamente associada a um periódico. Joaquim Manuel de Macedo e Machado de Assis, por exemplo, foram dois autores que não só divulgaram os seus romances nas folhas oitocentistas como também contribuíram com artigos jornalísticos, sobretudo Machado, que se dedicou à produção de crônicas durante aproximadamente 40 anos. Entretanto, nenhum deles esteve à frente de um grande jornal diário, assumindo o gerenciamento do que podia ou não ser publicado, incluindo aí a sua própria obra. O trabalho de José de Alencar no Diário do Rio de Janeiro não se restringiu assim ao de redator ou colaborador, mas foi além, na medida em que a sua atuação engendrou um campo letrado dentro do qual as esferas jornalística, editorial e literária confluíam de forma inédita em meados do Oitocentos. O autor de Lucíola soube aproveitar os meios de produção disponíveis para, em três anos, se lançar como escritor de diferentes modalidades discursivas, com as quais ele acabou lidando, com mais ou menos intensidade, no decorrer de sua carreira literária. Se o romancista obviamente se destacou no percurso, o cronista, o crítico e o dramaturgo continuaram se manifestando, como em "Beotices", "Bênção paterna" e $O$ jesuita, respectivamente. Debruçar-se sobre esse momento tão fértil da produção de José de Alencar, no vínculo que ela possui com esse campo gerado pelo entrecruzamento de distintas esferas culturais, ajuda-nos a entender de modo específico a obra inicial alencariana em sua primeira aparição pública, como também permite a reinterpretação de sua trajetória literária. 


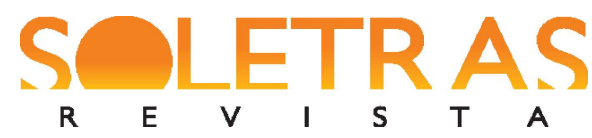

N. 40 - 2020.2 - MARCUS VINICIUS NOGUEIRA SOARES

\section{Referências}

ALENCAR, José de. Ao correr da pena (revista). Diário do Rio de Janeiro, Rio de Janeiro, ano 34, n. 2 ( $2^{\text {a }}$ série), 7 out. 1855. Folhetim, p. 1. Disponível em: http://memoria.bn.br/ DocReader/docreader.aspx bib $=094170 \_01 \&$ pasta $=$ ano $\% 20185 \&$ pesq $=$. Acesso em: 26 maio 2020 .

. Cartas sobre a Confederação dos Tamoios. Rio de Janeiro: Empresa Tipográfica do Diário, 1856 a.

. Cinco minutos. Diário do Rio de Janeiro, Rio de Janeiro, ano 35, n. 352, 22 dez. 1856b. Folhetim, p. 1. Disponível: http://memoria.bn.br/DocReader/docreader. aspx? bib $=094170 \_01 \&$ pasta $=$ ano\%20185\&pesq $=$. Acesso em: 20 abr. 2020.

. Cinco minutos. Diário do Rio de Janeiro, Rio de Janeiro, ano 35, n. 353, 23 dez. 1856c. Folhetim, p. 1. Disponível em: http://memoria.bn.br/DocReader/DocReader. aspx?bib=094170_01\&PagFis=44146. Acesso em: 20 abr. 2020.

. Cinco minutos. Diário do Rio de Janeiro, Rio de Janeiro, ano 35, n. 359, 30 dez. 1856d. Folhetim, p. 1. Disponível em: http://memoria.bn.br/DocReader/DocReader. aspx? bib=094170_01\&PagFis=44146. Acesso: 25 abr. 2020.

O guarani. Diário do Rio de Janeiro, Rio de Janeiro, ano 36, n. 1, 1 jan. 1857a. Folhetim, p. 1. Disponível em: http://memoria.bn.br/DocReader/DocReader.aspx? bib= 094170_01\&PagFis=44146. Acesso em: 30 abr. 2020.

. O guarani. Diário do Rio de Janeiro, Rio de Janeiro, ano 36, n. 17, 17 jan. 1857b, p. 1. Disponível em: http://memoria.bn.br/DocReader/DocReader.aspx?bib=094170_ 01 \& PagFis=44146. Acesso em: 30 abr. 2020.

O guarani. Diário do Rio de Janeiro, Rio de Janeiro, ano 36, n. 96, 9 abr. 1857c, p. 1. Disponível em: http://memoria.bn.br/DocReader/docreader.aspx?bib=094170_01\&pasta=ano $\% 20185 \&$ pesq $=\&$ pagfis $=44562$. Acesso em: 9 jul. 2020 .

O guarani. Diário do Rio de Janeiro, Rio de Janeiro, ano 36, n. 106, 20 abr. 1857d, p. 1. Disponível em: http://memoria.bn.br/DocReader/docreader.aspx?bib=094170_01\&pasta $=$ ano $\% 20185 \&$ pesq $=\&$ pagfis $=44602$. Acesso em: 9 jul. 2020 .

. A viuvinha. Diário do Rio de Janeiro, Rio de Janeiro, ano 36, n. 107, 21 abr.1857e. Folhetim, p. 1. Disponível em: http://memoria.bn.br/DocReader/DocReader.aspx? bib= 094170_01\&PagFis=44146. Acesso em: 28 abr. 2020.

A noite de S. João. Diário do Rio de Janeiro, Rio de Janeiro, ano 36, n. 292, 26 out. 1857f. Folhetim, p. 1. Disponível em: http://memoria.bn.br/DocReader/DocReader. aspx?bib=094170_01\&PagFis=44146. Acesso em: 27 abr. 2020.

Iracema: lenda do Ceará. Rio de Janeiro: Tipografia de Viana \& filhos, 1865. 
. As minas de prata. Rio de Janeiro: Garnier, 1866. v. 5.

. Sonhos d'ouro. Rio de Janeiro: Garnier, 1872.

1893.

. Como e porque sou romancista. Rio de Janeiro: Tipografia de G. Leuzinger \& filhos,

ALENCAR, Leonel de. Livro do domingo. Diário do Rio de Janeiro, Rio de Janeiro, ano 34, n. 77 ( $2^{\mathrm{a}}$ série), 23 dez. 1855. Folhetim, p. 1. Disponível em: http://memoria.bn.br/ DocReader/DocReader.aspx?bib=094170_01\&PagFis=44146. Acesso em: 22 abr. 2020.

Livro de domingo. Diário do Rio de Janeiro, Rio de Janeiro, ano 35, n. 167, 16 jun. 1856. Folhetim, p. 1. Disponível: http://memoria.bn.br/DocReader/DocReader. aspx? bib=094170_01\&PagFis=44146. Acesso em: 5 maio 2020.

AO VOAR da pena. O Correio da Tarde: jornal comercial, político, literário e noticioso, Rio de Janeiro, ano 1, n. 1, 7 ago. 1855. Variedade, p. 3. Disponível em: http://memoria.bn.br/DocReader/docreader.aspx?bib=090000\&pasta=ano\%20185\&pesq $=$. Acesso em: 12 abr. 2020.

AOS NOSSOS leitores. Diário do Rio de Janeiro, Rio de Janeiro, ano 34, n. 46 (2a série), 21 nov. 1855. Diário, p. 1. Disponível em: http://memoria.bn.br/DocReader/ DocReader .aspx?bib=094170_01\&PagFis=44146. Acesso em: 2 maio 2020.

BOLETIM do dia. Diário do Rio de Janeiro, Rio de Janeiro, ano 35, n. 167, p.1, 16 jun. 1856a. Disponível em: http://memoria.bn.br/DocReader/DocReader.aspx?bib=094170 01\&PagFis=44146. Acesso em: 4 maio 2020.

BOLETIM do dia. Diário do Rio de Janeiro, Rio de Janeiro, ano 35, n. 170, p. 1, 19 jun. 1856b. Disponível em: http://memoria.bn.br/DocReader/DocReader.aspx?bib=094170 _01\&PagFis=44146. Acesso em: 19 maio 2020.

BOLETIM do dia. Diário do Rio de Janeiro, Rio de Janeiro, ano 35, n. 197, p. 1,16 jul. 1856c. Disponível em: http://memoria.bn.br/DocReader/DocReader.aspx?bib=094170_ 01\&PagFis=44146. Acesso em: 15 maio 2020 .

CHARTIER, Roger. Do livro à leitura. In: (org.). Práticas de Leitura. Tradução: Cristiane Nascimento. São Paulo: Estação Liberdade, 1996. p. 77-105.

CRÔNICA diária. Diário do Rio de Janeiro, Rio de Janeiro, ano 35, n. 168,17 jun. 1856a. Rio de Janeiro, p. 1. Disponível em: http://memoria.bn.br/DocReader/DocReader .aspx?bib=094170_01\&PagFis=44146. Acesso em: 16 maio 2020.

CRÔNICA diária. Diário do Rio de Janeiro, Rio de Janeiro, ano 35, n. 352, 22 dez. 1856b. Rio de Janeiro, p. 1. Disponível em: http://memoria.bn.br/DocReader/DocReader. aspx?bib=094170_01\&PagFis=44146. Acesso em: 17 maio 2020. 
CRÔNICA diária. Diário do Rio de Janeiro, Rio de Janeiro, ano 35, n. 359, 30 dez. 1856c. Rio de Janeiro, p. 1. Disponível em: http://memoria.bn.br/DocReader/DocReader. aspx?bib=094170_01\&PagFis=44146. Acesso em: 17 maio 2020.

CRÔNICA diária. Diário do Rio de Janeiro, Rio de Janeiro, ano 35, n. 360, 31 dez. 1856d. Rio de Janeiro, p. 1. Disponível em: http://memoria.bn.br/DocReader/DocReader. aspx?bib=094170_01\&PagFis=44146. Acesso em: 18 maio 2020.

CRÔNICA diária. Diário do Rio de Janeiro, Rio de Janeiro, ano 36, n.130, 14 maio 1857. Rio de Janeiro, p. 1. Disponível em: http://memoria.bn.br/DocReader/ DocReader.aspx?bib=094170_01\&PagFis=44146. Acesso em: 22 maio 2020 .

CRÔNICA diária. Diário do Rio de Janeiro, Rio de Janeiro, ano 37, n. 155, 10 jun. 1858a. Rio de janeiro, p. 1. Disponível em: http://memoria.bn.br/ DocReader/DocReader.aspx?bib=094170_01\&PagFis=44146. Acesso em 1 jun. 2020.

CRÔNICA diária. Diário do Rio de Janeiro, Rio de janeiro, ano 37, n. 162, 17 jun. 1858b. Rio de Janeiro, p. 1. Disponível em: http://memoria.bn.br/ DocReader/DocReader. aspx?bib=094170_01\&PagFis=44146. Acesso em: 2 jun. 2020.

NETO, Henrique Maximiano Coelho. José de Alencar. Gazeta de Notícias, Rio de Janeiro, ano 23, n. 122, p. 1, 2 maio 1897. Disponível em: http://memoria.bn.br/DocReader/Doc Reader.aspx?bib=103730_03\&pagfis=16167. Acesso em: 12 jul. 2020.

NETO, Lira. O inimigo do rei: uma biografia de José de Alencar. São Paulo: Globo, 2006.

QUINZENA. Marmota Fluminense: jornal de modas e variedades, Rio de Janeiro, ano 2, n. 610, 12 ago. 1855. Folhetim, p. 1. Disponível em: http://memoria.bn.br/DocReader/ docreader.aspx?bib=706914\&pasta=ano\%20185\&pesq=. Acesso em: 23 maio 2020.

REVISTA do Ginásio. Correio Mercantil, Rio de Janeiro, ano 15, n. 147, 1 jun. 1858. Publicações a pedido, p. 2. Disponível em: http://memoria.bn.br/DocReader/docreader. aspx?bib=217280\&pasta $=$ ano $\% 20185 \&$ pesq $=$. Acesso em: 28 abr. 2020.

RIO de Janeiro, 13 de setembro. Diário do Rio de Janeiro, Rio de Janeiro, ano 34, n. 252, 13 set. 1855. O Diário, p. 1. Disponível em: http://memoria.bn.br/DocReader/ DocReader. aspx?bib=094170_01\&PagFis=44146. Acesso em: 10 abr. 2020.

\section{José de Alencar in the Diário de Rio de Janeiro}

Abstract: Between October 1855 and July 1858, José de Alencar held the position of editor in chief of the newspaper Diário do Rio de Janeiro. During this period, he was responsible for the publication of several works, mainly of his own authorship, on the pages of the Diário, contemplating various discursive genres, from literary criticism to romance, including opera libretto, biography, among others. In just three years at the helm of the newspaper, Alencar has become a recognized name in the intellectual circle of that time. The moment was so fertile that some of these works remain in evidence 


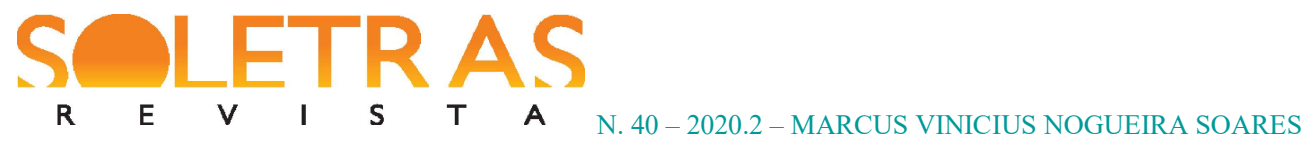

today in the author's critical fortune, such as Cartas sobre a Confederação dos Tamoios and $O$ guarani. Considering the material conditions of production and diffusion characteristic of journalism in the mid-19th century that made the public experience of these works possible, this article analyzes the importance of this initial moment in José de Alencar's career for the understanding of his intellectual and literary trajectory.

Keywords: José de Alencar. Brazilian novel. 19th century journalism.

Recebido em: 15 de junho de 2020 .

Aceito em: 17 de julho de 2020. 